\title{
Effects of temperature and doxorubicin exposure on keratinocyte damage in vitro
}

\author{
Francis-Paul E. M. Janssen - Carlijn V. C. Bouten • \\ Gerard M. J. van Leeuwen - Anton A. van Steenhoven
}

Received: 8 June 2007 / Accepted: 20 November 2007 / Published online: 11 January 2008 / Editor: J. Denry Sato

(C) The Society for In Vitro Biology 2007

\begin{abstract}
Cancer chemotherapy treatment often leads to hair loss, which may be prevented by cooling the scalp during drug administration. The current hypothesis for the hair preservative effect of scalp cooling is that cooling of the scalp skin reduces blood flow (perfusion) and chemical reaction rates. Reduced perfusion leads to less drugs available for uptake, whereas the reduced temperature decreases uptake of and damage by chemotherapy. Altogether, less damage is exerted to the hair cells, and the hair is preserved. However, the two mechanisms in the hypothesis have not been quantified yet. To quantify the effect of reduced drug damage caused by falling temperatures, we investigated the effect of local drug concentration and local tissue temperature on hair cell damage using in vitro experiments on keratinocytes. Cells were exposed for $4 \mathrm{~h}$ to a wide range of doxorubicin concentrations. During exposure, cells were kept at different temperatures. Cell viability was determined after $3 \mathrm{~d}$ using a viability test. Control samples were used to establish a concentrationviability curve. Results show that cell survival is significantly higher in cooled cells $\left(T<22^{\circ} \mathrm{C}\right)$ than in non-cooled cells $\left(T=37^{\circ} \mathrm{C}\right)$, but no significant differences are visible between $T=10^{\circ} \mathrm{C}$ and $T=22^{\circ} \mathrm{C}$. Based on this result and previous work, we can conclude that there is an optimal temperature in scalp cooling. Further cooling will only result in unnecessary discomfort for the patient and should therefore be avoided.
\end{abstract}

F.-P. E. M. Janssen $(\bowtie) \cdot$ C. V. C. Bouten

G. M. J. van Leeuwen - A. A. van Steenhoven

Department of Biomedical Engineering,

Eindhoven University of Technology,

PO Box 513, 5600 MB Eindhoven, The Netherlands

e-mail: f.e.m.janssen@tue.nl
Keywords Scalp cooling · Chemotherapy induced hair loss · Doxorubicin $\cdot$ Keratinocytes $\cdot$ Viability

\section{Introduction}

Chemotherapy-induced hair loss is a feared side effect of cancer treatment (Katsimbri et al. 2000). Scalp cooling during administration of chemotherapy prevents hair loss (e.g., Ridderheim et al. 2003). Cooling can be achieved by means of a cap that is pre-cooled in a freezer or that exchanges coolant with a reservoir. The hair preservative effect of scalp cooling is attributed both to reduced blood flow by vasoconstriction and to reduced reaction rates in the body at the level of the hair follicle. When the scalp is cooled, vasoconstriction is induced, and through this, blood flow to the hair follicle is decreased. This reduced blood flow results in a decrease of the total amount of cytotoxic drug available for uptake in the hair follicle. The effect of reduced perfusion was studied by Janssen et al. (2007), and it was found that cooling the scalp to $20^{\circ} \mathrm{C}$ reduces local blood flow down to $20 \%$ of normal. A further decrease in temperature did not result in a further decrease in local blood flow. Based on this, it might be expected that there is a limit in temperature below which the effectiveness of scalp cooling will not increase anymore.

However, the hair preservative effect of scalp cooling is also attributed to reduced cell metabolism. Because of reduced temperatures during scalp cooling, cellular drug uptake and damage are assumed to be lower, and with this, hair follicles are thought to be less susceptible to cytotoxic drugs. Decorti et al. (2003) showed that in vitro doxorubicin uptake in kidney cells at $37^{\circ} \mathrm{C}$ was 4.5 times higher than drug uptake at $4^{\circ} \mathrm{C}$. In addition, Decorti also showed that doxorubicin uptake is dependent on extracellular concen- 
tration. Unfortunately, no studies have been performed to quantify these processes in the human hair follicle.

For a better understanding of the functioning of scalp cooling, it is important to quantify the contribution of reduced drug uptake and drug damage, if any, on the hair preservative effect of scalp cooling. To this end, we investigated experimentally the relationship between doxorubicin exposure and cell damage at different temperatures using normal human epidermal keratinocytes.

Chemotherapy disrupts the rapidly dividing keratinocytes (the cells that actually produce the hair shaft) in the hair follicle (Cotsarelis and Millar 2001). Therefore, the use of keratinocytes as an in vitro model is indicative for chemotherapy-induced damage to the hair follicle. Moreover, human keratinocytes are commercially available and they are easy to cultivate, which means that with this model, a wide range of boundary conditions can quickly be investigated.

The goal of the experiments was to assess the effects of temperature and chemotherapy on keratinocyte survival.

\section{Materials and Methods}

Pooled neonatal normal human epidermal keratinocytes (NHEK) were obtained from Cambrex Bio Science Verviers, Belgium (catalog number CC-2507). These cells have a doubling time of approximately $24 \mathrm{~h}$. Cells were cultured in T-75 flasks at a seeding density of 3,500 cells $\mathrm{cm}^{2}$ under an atmosphere of $95 \%$ air and $5 \% \mathrm{CO}_{2}$ at $37^{\circ} \mathrm{C}$ using $15 \mathrm{ml}$ of keratinocyte general medium (KGM2; Cambrex Bio Science Verviers, catalog number CC-3107). Medium was refreshed the day after plating, and afterwards every other day until cells reached $70-80 \%$ confluence. Then, cells were harvested using $6 \mathrm{ml}$ of trypsin solution and subsequently cryopreserved in liquid nitrogen at a density of $1.2 \times 10^{6}$ cells per milliliter using $80 \%$ KGM2, $10 \%$ fetal bovine serum, and $10 \%$ dimethyl sulfoxide (DMSO).

For the experiments on the effect of temperature and chemotherapy on keratinocyte survival, third passage cells were plated in 24-well plates at a cell density of 6,000 cells per square centimeter. Cells were incubated at $37^{\circ} \mathrm{C}$ for a period of $24 \mathrm{~h}$ to allow the cells to recover from handling. Concentrations of doxorubicin in KGM2 $(0.01,0.04,0.1$, $0.5,1.0,3.0$, or $10.0 \mu \mathrm{g} \mathrm{ml}^{-1}$ ) were prepared. Cells were then exposed to $250 \mu$ of a specific doxorubicin concentration. Plates were incubated for $4 \mathrm{~h}$ at either a low temperature $\left(T_{\mathrm{L}}=10^{\circ} \mathrm{C}\right)$, a medium temperature $\left(T_{\mathrm{M}}=22^{\circ} \mathrm{C}\right)$, or a high temperature $\left(T_{\mathrm{H}}=37^{\circ} \mathrm{C}\right)$. For each combination of temperature and doxorubicin concentration, a sample size of eight was used. Cells receiving medium without any doxorubicin were used as a control group for each specific temperature.
At the end of the exposure time, doxorubicin was removed, and cells were washed with $500 \mu$ phosphate-buffered saline (PBS). Fresh medium $(250 \mu \mathrm{l}$ per well) was added to each well, and plates were then incubated at $37^{\circ} \mathrm{C}$ for a post-exposure time of $72 \mathrm{~h}$, after which, a viability assay was performed as described below.

The damage to the NHEK cells exposed to different temperatures and doxorubicin concentrations was determined by a colorimetric MTT (tetrazolium) viability assay. The assay is based on the observation that viable cells have the ability to metabolize a water-soluble tetrazolium dye 3(4,5-dimethylthiazol-2-yl)-2,5-diphenyl tetrazolium bromide (MTT) into a product termed purple formazan (Mosmann 1983; Edmondson et al., 1988; Sgouras and Duncan, 1990). The purple formazan can be solubilized, and the optical density of the solute can be determined using a spectrophotometric technique. The resulting absorbance is directly proportional to the number of cells, and this linearity extends over a wide range of cell numbers (Mosmann 1983). A standard MTT solution was prepared by dissolving $5 \mathrm{mg} \mathrm{ml}^{-1}$ of MTT (MTT formazan, Sigma Aldrich, Zwijndrecht, The Netherlands) in PBS. The standard MTT solution was added to complete medium (KGM2) in a ratio of 1 to 10 to obtain a final solution of $10 \%$ MTT solution and $90 \%$ KGM2. A volume of $220 \mu 1$ of this solution was added to all test wells, and the plates were left to incubate at $37^{\circ} \mathrm{C}$ and $5 \% \mathrm{CO}_{2}$ for a period of $45 \mathrm{~min}$. After this period, the MTT/medium solution was removed, and $200 \mu \mathrm{l}$ of a solution of $90 \%$ DMSO and $10 \%$ Triton $\mathrm{X}$ was added to extract the purple formazan salt from the cells. Plates were sealed and kept in dark for $30 \mathrm{~min}$, after which, $100 \mu \mathrm{l}$ of each well was transferred to a new well of a 96-well plate. The optical density (OD) was measured using an automated spectrophotometric plate reader (Synergy HT, BioTek Instruments Inc., Winooski, VT, USA) set to $570 \mathrm{~nm}$ and using a reference wavelength of $650 \mathrm{~nm}$. Blanks $(100 \mu \mathrm{l}$ of DMSO/Triton $\mathrm{X}$ solution only) were used as an extra control. For each well, the corrected optical density $\operatorname{OD}(570-650 \mathrm{~nm})$ was provided by the plate reader. Mean optical density and standard error of each temperature and concentration group [ODT,C $\pm \mathrm{SE}(\mathrm{ODT}, \mathrm{C})]$ and their respective control group [ODT, $0 \pm \mathrm{SE}(\mathrm{ODT}, 0)]$ were calculated. Based on these values, the viability $(S)$ for each temperature and concentration group can be calculated as:

$S_{\mathrm{T}, \mathrm{C}}=\frac{\mathrm{OD}_{\mathrm{T}, \mathrm{C}}}{\mathrm{OD}_{\mathrm{T}, \mathrm{C}}}$

An analysis of variance (ANOVA) was performed using statistical software (SPSS version 15.0, SPSS Inc., Chicago, IL). The ANOVA test is used to investigate whether significant differences in mean values exist between two 
or more groups. In this study, we want to investigate what the effect of temperature on the one hand, and the effect of doxorubicin concentration on the other hand, is on cell survival. Using a general linear model, the viability is statistically modeled as:

$S_{T, C}=\mu+\alpha T+\beta C+\gamma(T \cdot C)+\varepsilon$

This means that we investigated whether temperature, concentration, and an interaction term are significantly relevant for describing our data. Where appropriate, a post hoc analysis was used using Tamhane's T2 criterium (based on unequal variances) to test for differences between various doxorubicin concentrations and various exposure temperatures. A significance level of $p<0.05$ was used in these statistical tests.

\section{Results}

Microscopic photographs of cells at selected concentrations are shown in Fig. 1. Here, we can see that the control groups of all temperatures show similar cell counts. With increasing concentration, the number of cells decreases. At $3 \mu \mathrm{g} \mathrm{ml}^{-1}$ (C4), a clear difference is visible between the high temperature group and both the medium and low temperature group. The difference between these groups at other concentrations is less well defined. It can be seen that there is a difference in cell morphology between $0.04 \mu \mathrm{g} \mathrm{ml}^{-1}$ (C2) and $0.5 \mu \mathrm{g} \mathrm{ml}^{-1}$ (C3). Cells in the latter group, and in groups with higher doxorubicin concentrations, show enlarged and flattened cell shape and increased granularity. These are characteristics of senescence or aging, which is known to be caused by doxorubicin (Roninson 2003). The results of the viability determination are shown in Fig. 2.
Figure 1. Microscopic photographs of cells exposed to selected doxorubicin concentrations. Photographs are taken at a magnification of ten times. $\mathrm{C} 1=0.01 \mu \mathrm{g} \mathrm{ml}^{-1}, \mathrm{C} 2=$ $0.04 \mu \mathrm{g} \mathrm{ml}^{-1}, \mathrm{C} 3=0.5 \mu \mathrm{g} \mathrm{ml}^{-1}$, $\mathrm{C} 4=3.0 \mu \mathrm{g} \mathrm{ml}^{-1}, \mathrm{C} 5=$

$10 \mu \mathrm{g} \mathrm{ml}^{-1}$.

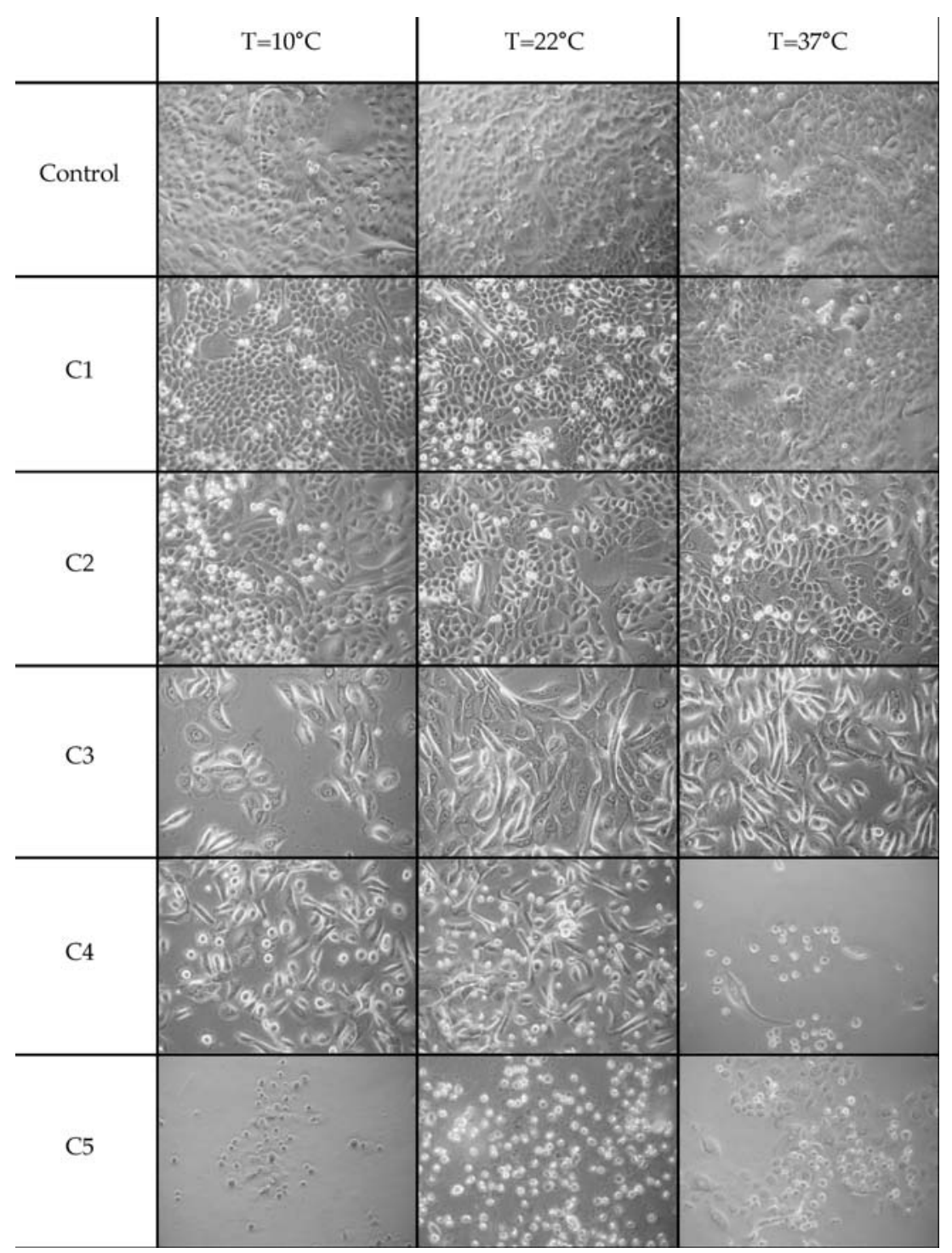




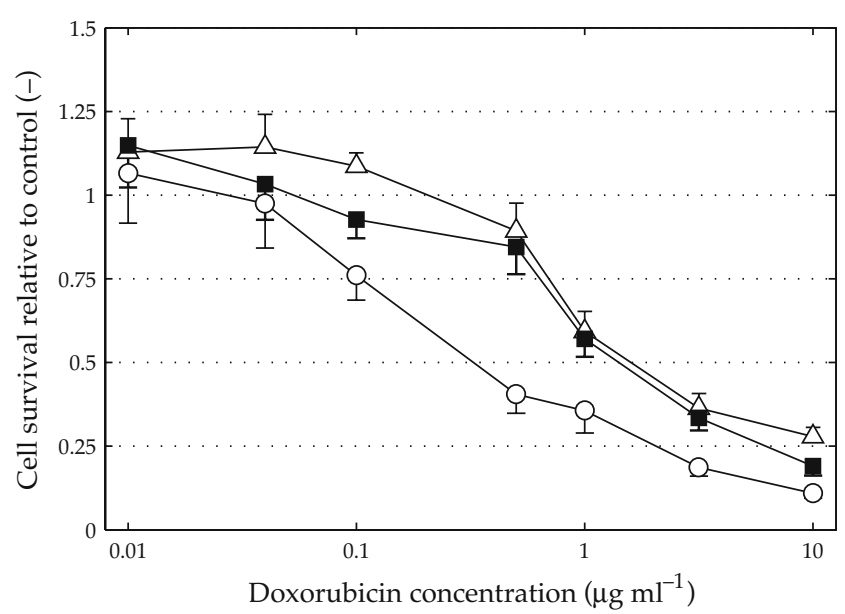

Figure 2. Cell viability as a function of doxorubicin concentration at different temperatures. Delta: $T_{\mathrm{L}}\left(10^{\circ} \mathrm{C}\right)$, filled square: $T_{\mathrm{M}}\left(22^{\circ} \mathrm{C}\right)$, and open circle: $T_{\mathrm{H}}\left(37^{\circ} \mathrm{C}\right)$. Data points show the mean and standard error of eight replicates. The results of a significance test are shown in Table 1.

This figure shows the cell viability as a function of doxorubicin concentration for different doxorubicin exposure temperatures. In this figure, we can see that the viability of keratinocytes as a function of doxorubicin concentration shows a decreasing S-curve with increasing concentrations. Viability levels are slightly above 1 for low concentrations $\left(0.01 \mu \mathrm{g} \mathrm{ml}^{-1}\right)$, and with increasing concentrations, viability gradually drops towards zero for high concentrations $\left(10 \mu \mathrm{g} \mathrm{ml}^{-1}\right)$. For different temperature groups, cell viability at a specific concentration is always lowest for the high temperature group. In the mid-section of the concentration range (i.e., $0.1-1 \mu \mathrm{g} \mathrm{ml}^{-1}$ ), the differences between the high temperature group $\left(T_{\mathrm{H}}\right)$ and the two lower temperature groups $\left(T_{\mathrm{L}}\right.$ and $\left.T_{\mathrm{M}}\right)$ are more pronounced. Cell viability for these lower temperature groups decreases more slowly than for the high temperature group, until at a concentration of $1 \mu \mathrm{g} \mathrm{ml}^{-1}$, a rapid drop in cell viability is visible. The difference between the individual temperature groups at low and high concentrations is therefore small.
From an ANOVA analysis, we found that the effect of doxorubicin concentration on NHEK viability was highly significant $[F(6,161)=165.213, p<0.001]$, as was the effect of temperature on NHEK viability $[F(6,161)=37.054, p<$ 0.001]. The effect size of doxorubicin $\left(\eta_{\mathrm{p}}^{2}\right.$; partial eta squared) was higher than the effect size of temperature $\left(\eta_{\mathrm{p}}^{2}=0.88\right.$ compared to $\left.\eta_{\mathrm{p}}^{2}=0.36\right)$.

For all temperature groups, increased doxorubicin concentration has a significant decreasing effect on cell viability. This effect was highly significant for the high temperature group $[F(6,49)=119.400, p<0.001]$, the intermediate temperature group $[F(6,49)=33.166, p<0.001]$, and the lowest temperature group $[F(6,49)=68.225, p<$ 0.001] Based on these results, a post hoc analysis was performed for each temperature group to check where a significant transition in cell viability as function of doxorubicin concentration occurs. This transition point may be viewed as the inflection point of the S-curve. For the low and medium temperature group, we found a transition point between 1.0 and $3.0 \mu \mathrm{g} \mathrm{ml}^{-1}$. The highest temperature group has a transition point slightly below $0.5 \mu \mathrm{g} \mathrm{ml}^{-1}$.

The ANOVA analysis also revealed a significant interaction between doxorubicin and temperature on cell viability $[F(6,161)=2.754, p=0.002]$, although the effect is smaller than that of temperature and doxorubicin $\left(\eta_{\mathrm{p}}^{2}=\right.$ 0.199). This significant interaction term shows that the effect of temperature on cell viability is not the same at the levels of different doxorubicin concentrations. For low and high doxorubicin concentrations, there is hardly any influence of a lower temperature on cell survival. In the mid-section of the graph this influence is far more substantial.

The results of the ANOVA analysis are summarized in Table 1. It can be seen that significant differences exist between $T_{\mathrm{L}}$ and $T_{\mathrm{H}}$ for concentrations of $0.1 \mu \mathrm{g} \mathrm{ml}^{-1}$ and up, except for a concentration of $1 \mu \mathrm{g} \mathrm{ml}^{-1}$. At this concentration, the significance level is not high enough, but still, a trend is visible $(p<0.1)$. Between $T_{\mathrm{M}}$ and $T_{\mathrm{H}}$,

Table 1. Results of an ANOVA analysis for determining the significance between different temperature groups at a specific doxorubicin concentration

\begin{tabular}{lllll}
\hline Doxorubicin $\left(\mu \mathrm{g} \mathrm{ml}^{-1}\right)$ & $F$ value & $p$ value & $T_{\mathrm{L}}$ vs $T_{\mathrm{H}}$ & $T_{\mathrm{M}}$ vs $T_{\mathrm{H}}$ \\
\hline 0.01 & $F(2,21)=0.315$ & 0.733 & & \\
0.04 & $F(2,21)=1.958$ & 0.166 & & $p<0.1 *$ \\
0.1 & $F(2,21)=15.187$ & $<0.001$ & $p<0.01$ & $p<0.001$ \\
0.5 & $F(2,21)=31.605$ & $<0.001$ & $p<0.001$ & $p<0.01$ \\
1 & $F(2,21)=4.380$ & $<0.05$ & $p<0.1 *$ & $p<0.05$ \\
3 & $F(2,21)=12.908$ & $<0.001$ & $p<0.01$ & $p<0.05$ \\
10 & $F(2,21)=22.587$ & $<0.001$ & $p<0.001$ & $p$ \\
\hline
\end{tabular}

$p$ Values are shown with their respective significance level. Trends $(p<0.1)$ are marked with an asterisk. See text for more detail. 
significant differences exist for concentrations of $0.5 \mu \mathrm{g} \mathrm{ml}{ }^{-1}$ and up, except for a concentration of $1 \mu \mathrm{g} \mathrm{ml}^{-1}$ where no significant difference is visible. The only significant difference between $T_{\mathrm{L}}$ and $T_{\mathrm{M}}$ exists at a concentration of $10 \mu \mathrm{g} \mathrm{ml}^{-1}$, although a trend is visible at a concentration of $0.1 \mu \mathrm{g} \mathrm{ml}^{-1}$.

\section{Discussion}

We examined the role reduced metabolism has on the hair preservative effect of scalp cooling. For this, a controlled in vitro experiment was conducted to assess the damage exerted by doxorubicin on human epidermal keratinocytes for a range of chemotherapy concentrations and exposure temperatures. The effects of temperature and doxorubicin on cell damage were determined from cell viability measurements (MTT assay).

We found that increased doxorubicin concentrations have a significant decreasing effect on keratinocyte cell viability. Viability was close to 1 for low concentrations and close to 0 for high concentrations. In between, the relationship between doxorubicin concentration and cell viability shows an Scurve. We also found that reduced temperature has a significant increasing effect on keratinocyte cell viability. The two cooled temperature groups $\left(10^{\circ} \mathrm{C}\right.$ and $\left.22^{\circ} \mathrm{C}\right)$ show a higher cell viability for each doxorubicin concentration than the $37^{\circ} \mathrm{C}$ group. At the mid-range of doxorubicin concentrations $\left(0.04-1 \mu \mathrm{g} \mathrm{ml}{ }^{-1}\right)$, the effect of reduced temperature is more pronounced than in the extreme values of doxorubicin concentration. This observation is confirmed by the fact that an interaction term of doxorubicin concentration and exposure temperature was significant. The increased effect of reduced temperature was significant for doxorubicin concentrations of $0.1 \mu \mathrm{g} \mathrm{ml}^{-1}$ and higher. We found no significant differences between the low $\left(10^{\circ} \mathrm{C}\right)$ and medium $\left(22^{\circ} \mathrm{C}\right)$ group.

The results of the experiment are in line with the hypothesis of scalp cooling. In this hypothesis, the reduced temperature caused by scalp cooling will result in lower perfusion and a lower cellular metabolism. With this, the supply, uptake and damage of a chemotherapeutic agent will be diminished.

For low doxorubicin concentrations $(0.01$ and $0.04 \mu \mathrm{g}$ $\mathrm{ml}^{-1}$ ), the MTT assay for each temperature group showed a higher viability than the respective control group. Because of the fact that each specific temperature group has its own control group, it is unlikely that this effect is caused by a measurement error. This means that apparently, cells are metabolically more active when exposed to a small amount of doxorubicin. It is possible that cells in the control group are close to reaching confluence at the time that viability is determined. As cells reach confluence, there is not enough room for new cells. Therefore, the rate at which cells divide will become lower, and hence, their metabolic activity will decrease. Another possibility is that a small amount of doxorubicin will stimulate cells to repair damage exerted to the cells. Hence, it may actually result in larger cell growth compared to a control group receiving no doxorubicin. At this point, however, we have no indication for which explanation may be true.

Another remarkable result is that there is no significant difference between the medium and low temperature group. Thus, it seems that there is a limit in effect of reduced temperature. In a pilot study to determine optimal doxorubicin exposure temperature, we found that an exposure temperature of $26^{\circ} \mathrm{C}$ also showed increased cell viability (data not shown), and this increase did not differ from other temperature groups. During scalp cooling, a skin temperature of approximately $20^{\circ} \mathrm{C}$ is reached. Based on the results of our experiment, one might expect that the limit in effect of reduced temperature during scalp cooling may be reached for a temperature as high as $26^{\circ} \mathrm{C}$. This means that during scalp cooling, the effect of reduced metabolism is already at its maximum. However, care has to be taken when the results of an in vitro experiment are generalized. Therefore, further studies on the effect of reduced temperature on cell damage are needed to exactly define this limit. Ideally, an in vitro hair follicle model is used in these studies. Our current study confines the boundary conditions in doxorubicin concentration and exposure temperature that can be used in these further studies.

Recently, it was shown that there is a limit in perfusion during scalp cooling (Janssen et al. 2007). Cooling the scalp to approximately $18^{\circ} \mathrm{C}$ resulted in a decrease in perfusion to $20 \%$. Further cooling did not result in any further decrease in perfusion. The findings of the current study indicate that there is no difference in cell survival between $22^{\circ} \mathrm{C}$ and $10^{\circ} \mathrm{C}$. Based on these findings, we can conclude that there is an optimal temperature in scalp cooling. Further cooling will only result in unnecessary discomfort for the patient. Therefore, strong cooling during scalp cooling should be avoided.

Acknowledgments This project was sponsored by SOBU, an administrative cooperation between Tilburg University and the Eindhoven University of Technology.

\section{References}

Cotsarelis, G.; Millar, S. Towards a molecular understanding of hair loss and its treatment. Trends Mol Med. 7(7):293-301; 2001.

Decorti, G.; Peloso, I.; Favarin, D.; Klugmann, F.; Candussio, L.; Crivellato, E.; Mallardi, F.; Baldini, L. Handling of doxorubicin by the LLC-PK1 kidney epithelial cell line. J Pharm Exp Ther. 125(1):832-840; 2003.

Edmondson, J.M.; Armstrong, L.S.; Martinez, A.O. A rapid and simple MTT-based spectrophotometric assay for determining drug 
sensitivity in monolayer cultures. J Tiss Cult Meth. 11(1):15-17; 1988.

Janssen, F.E.M.; Rajan, V.; Steenbergen, W.; Van Leeuwen, G.M.J.; Van Steenhoven, A.A. The relationship between local scalp skin temperature and cutaneous perfusion during scalp cooling. Physiol Meas 28:829-839; 2007.

Katsimbri, P.; Bamias, A.; Pavlidis, N. Prevention of chemotherapy induced alopecia using an effective scalp cooling system. Eur J Cancer. 36(6):766-771; 2000.

Mosmann, T. Rapid colorimetric assay for cellular growth and survival: Application to proliferation and cytotoxicity assays. J Immunol Methods. 65:55-63; 1983.
Ridderheim, M.; Bjurberg, M.; Gustavsson, A. Scalp hypothermia to prevent chemotherapy-induced alopecia is effective and safe: A pilot study of a new digitized scalp-cooling system used in 74 patients. Support Care Cancer. 11(6):371-377; 2003.

Roninson, I.B. Tumor Cell Senescence in Cancer Treatment. Cancer Res. 63:2705-2715; 2003.

Sgouras, D.; Duncan, R. Methods for the evaluation of biocompatibility of soluble synthetic polymers which have potential for biomedical use: 1-Use of the tetrazolium-based colorimetric assay (MTT) as a preliminary screen for evaluation of in vitro cytotoxicity. J Mater Sci Mater Med. 1:61-68; 1990. 